Joachim Eibach, Inken Schmidt-Voges (Hrsg.)

Das Haus in der Geschichte Europas 



\section{Das Haus}

in der Geschichte

\section{Europas}

Ein Handbuch

Herausgegeben von Joachim Eibach und Inken SchmidtVoges, in Verbindung mit Simone Derix, Philip Hahn, Elizabeth Harding und Margareth Lanzinger

Redaktion: Roman Bonderer 
Gedruckt mit Unterstützung der Fritz Thyssen Stiftung für Wissenschaftsförderung.

ISBN 978-3-11-035888-9

eISBN (PDF) 978-3-11-035898-8

eISBN (EPUB) 978-3-11-035899-5

\section{Library of Congress Cataloging-in-Publication Data}

A CIP catalog record for this book has been applied for at the Library of Congress.

\section{Bibliografische Information der Deutschen Nationalbibliothek}

Die Deutsche Nationalbibliothek verzeichnet diese Publikation in der Deutschen Nationalbibliografie; detaillierte bibliografische Daten sind im Internet über http://dnb.dnb.de abrufbar.

(C) 2015 Walter de Gruyter GmbH, Berlin/Boston

Titelbild: Johann Friedrich Penther, Ausführliche Anleitung zur bürgerlichen Bau-Kunst, Augs-

burg 1745. Universitätsbibliothek Heidelberg / 64 D 5 RES::1 / Tafel XIV

Satz: le-tex publishing services $\mathrm{GmbH}$, Leipzig

Druck und Bindung: $\mathrm{CPI}$ books $\mathrm{GmbH}$, Leck

@ Gedruckt auf säurefreiem Papier

Printed in Germany

www.degruyter.com 